\title{
Necessary and Sufficient Condition for Mann Iteration Converges to a Fixed Point of Lipschitzian Mappings
}

\author{
Chang-He Xiang, ${ }^{1}$ Jiang-Hua Zhang, ${ }^{2}$ and Zhe Chen ${ }^{1}$ \\ ${ }^{1}$ College of Mathematics, Chongqing Normal University, Chongqing 400047, China \\ 2 School of Management, Shandong University, Shandong Jinan 250100, China
}

Correspondence should be addressed to Jiang-Hua Zhang, zhangjianghua28@163.com

Received 18 July 2012; Revised 2 September 2012; Accepted 2 September 2012

Academic Editor: Jian-Wen Peng

Copyright (c) 2012 Chang-He Xiang et al. This is an open access article distributed under the Creative Commons Attribution License, which permits unrestricted use, distribution, and reproduction in any medium, provided the original work is properly cited.

Suppose that $E$ is a real normed linear space, $C$ is a nonempty convex subset of $E, T: C \rightarrow C$ is a Lipschitzian mapping, and $x^{*} \in C$ is a fixed point of $T$. For given $x_{0} \in C$, suppose that the sequence $\left\{x_{n}\right\} \subset C$ is the Mann iterative sequence defined by $x_{n+1}=\left(1-\alpha_{n}\right) x_{n}+\alpha_{n} T x_{n}, n \geq 0$, where $\left\{\alpha_{n}\right\}$ is a sequence in [0,1], $\sum_{n=0}^{\infty} \alpha_{n}^{2}<\infty, \sum_{n=0}^{\infty} \alpha_{n}=\infty$. We prove that the sequence $\left\{x_{n}\right\}$ strongly converges to $x^{*}$ if and only if there exists a strictly increasing function $\Phi:[0, \infty) \rightarrow[0, \infty)$ with $\Phi(0)=0$ such that $\lim \sup _{n \rightarrow \infty} \inf _{j\left(x_{n}-x^{*}\right) \in J\left(x_{n}-x^{*}\right)}\left\{\left\langle T x_{n}-x^{*}, j\left(x_{n}-x^{*}\right)\right\rangle-\left\|x_{n}-x^{*}\right\|^{2}+\Phi\left(\left\|x_{n}-x^{*}\right\|\right)\right\} \leq 0$.

\section{Introduction}

Let $E$ be an arbitrary real normed linear space with dual space $E^{*}$, and let $C$ be a nonempty subset of $E$. We denote by $J$ the normalized duality mapping from $E$ to $2^{E^{*}}$ defined by

$$
J(x)=\left\{f \in E^{*}:\langle x, f\rangle=\|x\|^{2}=\|f\|^{2}\right\}, \quad \forall x \in E,
$$

where $\langle\cdot, \cdot\rangle$ denotes the generalized duality pairing.

A mapping $T: C \rightarrow E$ is called strongly pseudocontractive if there exists a constant $k \in(0,1)$ such that, for all $x, y \in C$, there exists $j(x-y) \in J(x-y)$ satisfying

$$
\langle T x-T y, j(x-y)\rangle \leq(1-k)\|x-y\|^{2} .
$$


$T$ is called $\phi$-strongly pseudocontractive if there exists a strictly increasing function $\phi:[0, \infty) \rightarrow$ $[0, \infty)$ with $\phi(0)=0$ such that, for all $x, y \in C$, there exists $j(x-y) \in J(x-y)$ satisfying

$$
\langle T x-T y, j(x-y)\rangle \leq\|x-y\|^{2}-\phi(\|x-y\|)\|x-y\|
$$

$T$ is called generalized $\Phi$-pseudocontractive (see, e.g., [1]) if there exists a strictly increasing function $\Phi:[0, \infty) \rightarrow[0, \infty)$ with $\Phi(0)=0$ such that

$$
\langle T x-T y, j(x-y)\rangle \leq\|x-y\|^{2}-\Phi(\|x-y\|)
$$

holds for all $x, y \in C$ and for some $j(x-y) \in J(x-y)$.

Let $F(T)=\{x \in C: T x=x\}$ denote the fixed point set of $T$. If $F(T) \neq \emptyset$, and (1.3) and (1.4) hold for all $x \in C$ and $y \in F(T)$, then the corresponding mapping $T$ is called $\phi$-hemicontractive and generalized $\Phi$-hemicontractive, respectively. It is well known that these kinds of mappings play important roles in nonlinear analysis.

$\phi$-hemicontractive (resp., generalized $\Phi$-hemicontractive) mapping is also called uniformly pseudocontractive (resp., uniformly hemicontractive) mapping in [2,3]. It is easy to see that if $T$ is generalized $\Phi$-hemicontractive mapping, then $F(T)$ is singleton.

It is known (see, e.g., $[4,5]$ ) that the class of strongly pseudocontractive mappings is a proper subset of the class of $\phi$-strongly pseudocontractive mappings. By taking $\Phi(s)=s \phi(s)$, where $\phi:[0, \infty) \rightarrow[0, \infty)$ is a strictly increasing function with $\phi(0)=0$, we know that the class of $\phi$-strongly pseudocontractive mappings is a subset of the class of generalized $\Phi$ pseudocontractive mappings. Similarly, the class of $\phi$-hemicontractive mappings is a subset of the class of generalized $\Phi$-hemicontractive mappings. The example in [6] demonstrates that the class of Lipschitzian $\phi$-hemicontractive mappings is a proper subset of the class of Lipschitzian generalized $\Phi$-hemicontractive mappings.

It is well known (see, e.g., [7]) that if $C$ is a nonempty closed convex subset of a real Banach space $E$ and $T: C \rightarrow C$ is a continuous strongly pseudocontractive mapping, then $T$ has a unique fixed point $p \in C$. In 2009, it has been proved in [8] that if $C$ is a nonempty closed convex subset of a real Banach space $E$ and $T: C \rightarrow C$ is a continuous generalized $\Phi$-pseudocontractive mappings, then $T$ has a unique fixed point $p \in C$.

Many results have been proved on convergence or stability of Ishikawa iterative sequences (with errors) or Mann iterative sequences (with errors) for Lipschitzian $\phi$ hemicontractive mappings or Lipschitzian generalized $\Phi$-hemicontractive mapping (see, e.g., [4-6, 9-12] and the references therein). In 2010, Xiang et al. [6] proved the following result.

Theorem XCZ (see [6, Theorem 3.2]). Let $E$ be a real normed linear space, let $C$ be a nonempty convex subset of $E$, and let $T: C \rightarrow C$ be a Lipschitzian generalized $\Phi$-hemicontractive mapping. For given $x_{0} \in C$, suppose that the sequence $\left\{x_{n}\right\} \subset C$ is the Mann iterative sequence defined by

$$
x_{n+1}=\left(1-\beta_{n}\right) x_{n}+\beta_{n} T x_{n}, \quad n \geq 0,
$$


where $\left\{\beta_{n}\right\}$ is a sequence in $[0,1]$ satisfying the following conditions:

(1) $\sum_{n=0}^{\infty} \beta_{n}=\infty$,

(2) $\sum_{n=0}^{\infty} \beta_{n}^{2}<\infty$.

Then $\left\{x_{n}\right\}$ converges strongly to the unique fixed point of $T$ in $C$.

The main purpose of this paper is to give necessary and sufficient condition for the Mann iterative sequence which converges to a fixed point of general Lipschitzian mappings in an arbitrary real normed linear space. As an immediate consequence, we will obtain necessary and sufficient condition for the Mann iterative sequence which converges to a solution of a general Lipschitzian operator equation $T x=f$.

\section{Preliminaries}

The following lemmas will be used in the proof of our main results.

Lemma 2.1 (see, e.g., [12]). Let $E$ be a real normed linear space. Then for all $x, y \in E$, we have

$$
\|x+y\|^{2} \leq\|x\|^{2}+2\langle y, j(x+y)\rangle, \quad \forall j(x+y) \in J(x+y) .
$$

Lemma 2.2 (see, e.g., [13]). Let $\left\{a_{n}\right\},\left\{b_{n}\right\},\left\{c_{n}\right\}$ be three nonnegative sequences satisfying the following condition:

$$
a_{n+1} \leq\left(1+b_{n}\right) a_{n}+c_{n}, \quad \forall n \geq n_{0}
$$

where $n_{0}$ is some nonnegative integer, $\sum_{n=n_{0}}^{\infty} b_{n}<\infty$, and $\sum_{n=n_{0}}^{\infty} c_{n}<\infty$. Then the limit $\lim _{n \rightarrow \infty} a_{n}$ exists.

Lemma 2.3. Suppose that $\varphi:[0, \infty) \rightarrow[0, \infty)$ is a strictly increasing function with $\varphi(0)=0$ and there exists a natural number $n_{0}$ such that $a_{n}, b_{n}, \varepsilon_{n}$, and $\alpha_{n}$ are nonnegative real numbers for all $n \geq n_{0}$ satisfying the following conditions:

(i) $a_{n+1} \leq\left(1+b_{n}\right) a_{n}-\alpha_{n} \varphi\left(a_{n+1}\right)+\alpha_{n} \varepsilon_{n}$, for all $n \geq n_{0}$,

(ii) $\sum_{n=n_{0}}^{\infty} b_{n}<\infty, \lim _{n \rightarrow \infty} \varepsilon_{n}=0$,

(iii) $\sum_{n=n_{0}}^{\infty} \alpha_{n}=\infty$.

Then $\lim _{n \rightarrow \infty} a_{n}=0$.

Proof. Without loss of generality, let $\lim _{n \rightarrow \infty} \inf a_{n}=a$. Now, we will show that $a=0$. Consider its contrary: $a>0$ or $a=\infty$. For any given $r \in(0, a)$, there exists a nonnegative integer $n_{1} \geq n_{0}$ such that $a_{n} \geq r>0$ and $\varepsilon_{n}<1 / 2 \varphi(r) \leq 1 / 2 \varphi\left(a_{n+1}\right)$ for all $n \geq n_{1}$. By condition (i), we have

$$
\begin{aligned}
a_{n+1} & \leq\left(1+b_{n}\right) a_{n}-\alpha_{n} \varphi\left(a_{n+1}\right)+\alpha_{n} \cdot \frac{1}{2} \varphi\left(a_{n+1}\right) \\
& =\left(1+b_{n}\right) a_{n}-\frac{1}{2} \alpha_{n} \varphi\left(a_{n+1}\right) \\
& \leq\left(1+b_{n}\right) a_{n}, \quad \forall n \geq n_{1} .
\end{aligned}
$$


Using Lemma 2.2 and condition (ii), we obtain that $\lim _{n \rightarrow \infty} a_{n}$ exists and $\left\{a_{n}\right\}$ is bounded. Suppose that $a_{n} \leq M$ (for all $n \geq n_{1}$ ), where $M$ is a nonnegative constant. It follows that

$$
a_{n+1} \leq\left(1+b_{n}\right) a_{n}-\frac{1}{2} \alpha_{n} \varphi\left(a_{n+1}\right) \leq a_{n}-\frac{1}{2} \alpha_{n} \varphi(r)+M b_{n}\left(\forall n \geq n_{1}\right) .
$$

Thus,

$$
\infty=\frac{1}{2} \varphi(r) \sum_{n=n_{1}}^{\infty} \alpha_{n} \leq a_{n_{1}}+M \sum_{n=n_{1}}^{\infty} b_{n}<\infty
$$

which is a contradiction. Therefore,

$$
\liminf _{n \rightarrow \infty} a_{n}=0
$$

By condition (ii), for all $\varepsilon>0$, there exists a nonnegative integer $n_{2} \geq n_{0}$ such that

$$
\varepsilon_{n}<\varphi(\varepsilon) \quad\left(\forall n \geq n_{2}\right), \quad \sum_{n=n_{2}}^{\infty} b_{n}<\ln 2
$$

By (2.6), there exists a natural number $N \geq n_{2}$ such that $a_{N}<\varepsilon$. Now, we prove the following inequality (2.8) holds for all $k \geq N$ :

$$
a_{k} \leq \varepsilon \cdot \exp \left(\sum_{n=N}^{k-1} b_{n}\right)
$$

It is obvious that (2.8) holds for $k=N$. Assuming (2.8) holds for some $k \geq N$, we prove that (2.8) holds for $k+1$. Suppose this is not true, that is, $a_{k+1}>\varepsilon \cdot \exp \left(\sum_{n=N}^{k} b_{n}\right)$. Then $a_{k+1} \geq \varepsilon$ and so $\varphi\left(a_{k+1}\right) \geq \varphi(\varepsilon)$. Noting that $1+b_{k} \leq \exp \left(b_{k}\right)$, it follows from condition (i), (2.7), and (2.8) that

$$
\begin{aligned}
a_{k+1} & \leq\left(1+b_{k}\right) a_{k}-\alpha_{k} \varphi\left(a_{k+1}\right)+\alpha_{k} \varepsilon_{k} \\
& \leq\left(1+b_{k}\right) a_{k}-\alpha_{k} \varphi(\varepsilon)+\alpha_{k} \varphi(\varepsilon) \\
& \leq \varepsilon \cdot\left(1+b_{k}\right) \exp \left(\sum_{n=N}^{k-1} b_{n}\right) \\
& \leq \varepsilon \cdot \exp \left(\sum_{n=N}^{k} b_{n}\right),
\end{aligned}
$$


which is a contradiction. This implies that (2.8) holds for $k+1$. By induction, (2.8) holds for all $k \geq N$. From (2.7), and (2.8), we have

$$
\limsup _{k \rightarrow \infty} a_{k} \leq \varepsilon \cdot \exp \left(\sum_{n=N}^{\infty} b_{n}\right)<2 \varepsilon .
$$

Taking $\varepsilon \rightarrow 0$, we obtain $\lim _{n \rightarrow \infty} \sup a_{k}=0$. By (2.6), we have $\lim _{n \rightarrow \infty} a_{n}=0$. This completes the proof.

Remark 2.4. Lemma 2.3 is different from Lemma 3 in [14], which requires that $b_{n}=0$ for all $n \geq 0$. It is also different from Lemma 2.3 in [6], which requires that $\sum_{n=n_{0}}^{\infty} \alpha_{n} \varepsilon_{n}<\infty$.

\section{Main Results}

Theorem 3.1. Let $E$ be a real normed linear space, $C$ be a nonempty convex subset of $E$, let $T: C \rightarrow C$ be a Lipschitzian mapping, and let $x^{*} \in C$ be a fixed point of $T$. For given $x_{0} \in C$, suppose that the sequence $\left\{x_{n}\right\} \subset C$ is the Mann iterative sequence defined by

$$
x_{n+1}=\left(1-\alpha_{n}\right) x_{n}+\alpha_{n} T x_{n}, \quad n \geq 0,
$$

where $\left\{\alpha_{n}\right\}$ is a sequence in $[0,1]$ satisfying the following conditions:

(i) $\sum_{n=0}^{\infty} \alpha_{n}^{2}<\infty$,

(ii) $\sum_{n=0}^{\infty} \alpha_{n}=\infty$.

Then $\left\{x_{n}\right\}$ converges strongly to $x^{*}$ if and only if there exists a strictly increasing function $\Phi$ : $[0, \infty) \rightarrow[0, \infty)$ with $\Phi(0)=0$ such that

$$
\limsup _{n \rightarrow \infty} \inf _{j\left(x_{n}-x^{*}\right) \in J\left(x_{n}-x^{*}\right)}\left\{\left\langle T x_{n}-x^{*}, j\left(x_{n}-x^{*}\right)\right\rangle-\left\|x_{n}-x^{*}\right\|^{2}+\Phi\left(\left\|x_{n}-x^{*}\right\|\right)\right\} \leq 0 .
$$

Proof. First, we prove the sufficiency of Theorem 3.1.

Suppose there exists a strictly increasing function $\Phi:[0, \infty) \rightarrow[0, \infty)$ with $\Phi(0)=0$ such that (3.2) holds. Let

$$
\gamma_{n}=\inf _{j\left(x_{n}-x^{*}\right) \in J\left(x_{n}-x^{*}\right)}\left\{\left\langle T x_{n}-x^{*}, j\left(x_{n}-x^{*}\right)\right\rangle-\left\|x_{n}-x^{*}\right\|^{2}+\Phi\left(\left\|x_{n}-x^{*}\right\|\right)\right\} .
$$

Then there exists $j\left(x_{n}-x^{*}\right) \in J\left(x_{n}-x^{*}\right)$ such that

$$
\left\langle T x_{n}-x^{*}, j\left(x_{n}-x^{*}\right)\right\rangle-\left\|x_{n}-x^{*}\right\|^{2}+\Phi\left(\left\|x_{n}-x^{*}\right\|\right)<\gamma_{n}+\frac{1}{n}, \quad \forall n \geq 1 .
$$

By (3.2), we obtain $\lim _{n \rightarrow \infty} \sup \gamma_{n} \leq 0$. Taking $\varepsilon_{n}=1 /(n+1)+\max \left\{\gamma_{n+1}, 0\right\} \quad$ (for all $n \geq 0$ ), then

$$
\lim _{n \rightarrow \infty} \varepsilon_{n}=0
$$


From (3.1) and (3.4), by using Lemma 2.1, we obtain

$$
\begin{aligned}
\| x_{n+1} & -x^{*} \|^{2} \\
= & \left\|\left(1-\alpha_{n}\right)\left(x_{n}-x^{*}\right)+\alpha_{n}\left(T x_{n}-x^{*}\right)\right\|^{2} \\
\leq & \left(1-\alpha_{n}\right)^{2}\left\|x_{n}-x^{*}\right\|^{2}+2 \alpha_{n}\left\langle T x_{n}-x^{*}, j\left(x_{n+1}-x^{*}\right)\right\rangle \\
\leq & \left(1-\alpha_{n}\right)^{2}\left\|x_{n}-x^{*}\right\|^{2}+2 \alpha_{n}\left\langle T x_{n+1}-x^{*}, j\left(x_{n+1}-x^{*}\right)\right\rangle \\
& +2 \alpha_{n}\left\langle T x_{n}-T x_{n+1}, j\left(x_{n+1}-x^{*}\right)\right\rangle \\
\leq & \left(1-\alpha_{n}\right)^{2}\left\|x_{n}-x^{*}\right\|^{2}+2 \alpha_{n}\left[\left\|x_{n+1}-x^{*}\right\|^{2}-\Phi\left(\left\|x_{n+1}-x^{*}\right\|\right)+\gamma_{n+1}+\frac{1}{n+1}\right] \\
& +2 L \alpha_{n}\left\|x_{n}-x_{n+1}\right\| \cdot\left\|x_{n+1}-x^{*}\right\| \\
\leq & \left(1-\alpha_{n}\right)^{2}\left\|x_{n}-x^{*}\right\|^{2}+2 \alpha_{n}\left[\left\|x_{n+1}-x^{*}\right\|^{2}-\Phi\left(\left\|x_{n+1}-x^{*}\right\|\right)+\varepsilon_{n}\right] \\
& +2 L \alpha_{n}\left\|x_{n}-x_{n+1}\right\| \cdot\left\|x_{n+1}-x^{*}\right\|,
\end{aligned}
$$

where $L$ is the Lipschitzian constant of $T$. It follows from (3.1) that

$$
\begin{aligned}
\left\|x_{n}-x_{n+1}\right\| & =\left\|\alpha_{n}\left(x_{n}-T x_{n}\right)\right\| \\
& \leq \alpha_{n}\left(\left\|x_{n}-x^{*}\right\|+\left\|T x^{*}-T x_{n}\right\|\right) \\
& \leq \alpha_{n}(1+L)\left\|x_{n}-x^{*}\right\| .
\end{aligned}
$$

Substituting (3.7) into (3.6), we have

$$
\begin{aligned}
\left\|x_{n+1}-x^{*}\right\|^{2} \leq & \left(1-\alpha_{n}\right)^{2}\left\|x_{n}-x^{*}\right\|^{2}+2 \alpha_{n}\left\|x_{n+1}-x^{*}\right\|^{2}-2 \alpha_{n} \Phi\left(\left\|x_{n+1}-x^{*}\right\|\right) \\
& +2 \alpha_{n} \varepsilon_{n}+2 L(1+L) \alpha_{n}^{2}\left\|x_{n}-x^{*}\right\| \cdot\left\|x_{n+1}-x^{*}\right\| \\
& \leq\left(1-\alpha_{n}\right)^{2}\left\|x_{n}-x^{*}\right\|^{2}+2 \alpha_{n}\left\|x_{n+1}-x^{*}\right\|^{2}-2 \alpha_{n} \Phi\left(\left\|x_{n+1}-x^{*}\right\|\right) \\
& +2 \alpha_{n} \varepsilon_{n}+L(1+L) \alpha_{n}^{2}\left(\left\|x_{n}-x^{*}\right\|^{2}+\left\|x_{n+1}-x^{*}\right\|^{2}\right) .
\end{aligned}
$$

Setting $a_{n}=\left\|x_{n}-x^{*}\right\|^{2}$ (for all $\left.n \geq 0\right), \varphi(s)=2 \Phi(\sqrt{s})$, it follows from (3.8) that

$$
\begin{aligned}
a_{n+1} \leq & \left(1-\alpha_{n}\right)^{2} a_{n}+2 \alpha_{n} a_{n+1}-\alpha_{n} \varphi\left(a_{n+1}\right)+2 \alpha_{n} \varepsilon_{n} \\
& +L(1+L) \alpha_{n}^{2}\left(a_{n}+a_{n+1}\right) \\
= & {\left[1-2 \alpha_{n}+\alpha_{n}^{2}+L(1+L) \alpha_{n}^{2}\right] a_{n}+\left[2 \alpha_{n}+L(1+L) \alpha_{n}^{2}\right] a_{n+1} } \\
& -\alpha_{n} \varphi\left(a_{n+1}\right)+2 \alpha_{n} \varepsilon_{n} .
\end{aligned}
$$


It follows from condition (i) that $\lim _{n \rightarrow \infty}\left[2 \alpha_{n}+L(1+L) \alpha_{n}^{2}\right]=0$. Thus, there exists a natural number $n_{0}$ such that $2 \alpha_{n}+L(1+L) \alpha_{n}^{2} \leq 1 / 2$ for all $n \geq n_{0}$. Let

$$
b_{n}=\frac{1-2 \alpha_{n}+\alpha_{n}^{2}+L(1+L) \alpha_{n}^{2}}{1-2 \alpha_{n}-L(1+L) \alpha_{n}^{2}}-1=\frac{\alpha_{n}^{2}+2 L(1+L) \alpha_{n}^{2}}{1-2 \alpha_{n}-L(1+L) \alpha_{n}^{2}}, \quad \forall n \geq n_{0} .
$$

Since $1 / 2 \leq 1-2 \alpha_{n}-L(1+L) \alpha_{n}^{2} \leq 1$ for all $n \geq n_{0}$, by (3.9) and (3.10), we have

$$
\begin{gathered}
a_{n+1} \leq\left(1+b_{n}\right) a_{n}-\alpha_{n} \varphi\left(a_{n+1}\right)+4 \alpha_{n} \varepsilon_{n}, \quad \forall n \geq n_{0}, \\
0 \leq b_{n} \leq 2[1+2 L(1+L)] \alpha_{n}^{2}, \quad \forall n \geq n_{0} .
\end{gathered}
$$

It follows from condition (i) that $\sum_{n=n_{0}}^{\infty} b_{n}<\infty$. Therefore, by (3.5), condition (ii), and Lemma 2.3, we obtain that $\lim _{n \rightarrow \infty} a_{n}=\lim _{n \rightarrow \infty}\left\|x_{n}-x^{*}\right\|^{2}=0$. That is, $\left\{x_{n}\right\}$ converges strongly to $x^{*}$.

Finally, we prove the necessity of Theorem 3.1.

Assume that $\left\{x_{n}\right\}$ converges strongly to $x^{*}$. Let $L$ be the Lipschitzian constant of $T$. For all $j\left(x_{n}-x^{*}\right) \in J\left(x_{n}-x^{*}\right)$, we have

$$
\left|\left\langle T x_{n}-x^{*}, j\left(x_{n}-x^{*}\right)\right\rangle\right| \leq L\left\|x_{n}-x^{*}\right\|^{2} .
$$

Taking $\Phi(s)=\sqrt{s}$, then $\Phi:[0, \infty) \rightarrow[0, \infty)$ is a strictly increasing function with $\Phi(0)=0$, and $\lim _{n \rightarrow \infty} \Phi\left(\left\|x_{n}-x^{*}\right\|\right)=0$. From (3.12), we obtain

$$
\lim _{n \rightarrow \infty j\left(x_{n}-x^{*}\right) \in J\left(x_{n}-x^{*}\right)}\left\{\left\langle T x_{n}-x^{*}, j\left(x_{n}-x^{*}\right)\right\rangle-\left\|x_{n}-x^{*}\right\|^{2}+\Phi\left(\left\|x_{n}-x^{*}\right\|\right)\right\}=0,
$$

which implies (3.2) holds. This completes the proof of Theorem 3.1.

Remark 3.2. If $T: C \rightarrow C$ is a generalized $\Phi$-hemicontractive mapping, then (3.2) holds. By Theorem 3.1, we obtain Theorem XCZ.

Theorem 3.3. Let $E$ be a real Banach space, let $C$ be a nonempty closed convex subset of $E$, and let $T: C \rightarrow C$ be a Lipschitzian generalized $\Phi$-pseudocontractive mapping. For given $x_{0} \in C$, suppose that the sequence $\left\{x_{n}\right\} \subset C$ is the Mann iterative sequence defined by

$$
x_{n+1}=\left(1-\alpha_{n}\right) x_{n}+\alpha_{n} T x_{n}, \quad n \geq 0,
$$

where $\left\{\alpha_{n}\right\}$ is a sequence in $[0,1]$ satisfying the following conditions:

$$
\begin{aligned}
& \text { (1) } \sum_{n=0}^{\infty} \alpha_{n}=\infty, \\
& \text { (2) } \sum_{n=0}^{\infty} \alpha_{n}^{2}<\infty .
\end{aligned}
$$

Then $\left\{x_{n}\right\}$ converges strongly to the unique fixed point of $T$ in $C$.

Proof. By Theorem 2.1 in [8], $T$ has a unique fixed point $x^{*}$ in C. By Theorem 3.1, $\left\{x_{n}\right\}$ converges strongly to $x^{*}$. This completes the proof of Theorem 3.3. 
Theorem 3.4. Let $E$ be a real normed linear space, let $S: E \rightarrow E$ be a Lipschitzian operator, and let $f \in E$ and $x^{*}$ be a solution of the equation $S x=f$. For given $x_{0} \in E$, suppose that the sequence $\left\{x_{n}\right\}$ is the Mann iterative sequence defined by

$$
x_{n+1}=\left(1-\alpha_{n}\right) x_{n}+\alpha_{n}\left(f+x_{n}-S x_{n}\right), \quad n \geq 0,
$$

where $\left\{\alpha_{n}\right\}$ is a sequences in $[0,1]$ satisfying the following conditions:

(i) $\sum_{n=0}^{\infty} \alpha_{n}^{2}<\infty$,

(ii) $\sum_{n=0}^{\infty} \alpha_{n}=\infty$.

Then $\left\{x_{n}\right\}$ converges strongly to $x^{*}$ if and only if there exists a strictly increasing function $\Phi$ : $[0, \infty) \rightarrow[0, \infty)$ with $\Phi(0)=0$ such that

$$
\liminf _{n \rightarrow \infty} \sup _{j\left(x_{n}-x^{*}\right) \in J\left(x_{n}-x^{*}\right)}\left\{\left\langle S x_{n}-S x^{*}, j\left(x_{n}-x^{*}\right)\right\rangle-\Phi\left(\left\|x_{n}-x^{*}\right\|\right)\right\} \geq 0
$$

Proof. Define $T: E \rightarrow E$ by $T x=f+x-S x$. Since $S x^{*}=f$, we have $T x^{*}=x^{*}$. From (3.15), we obtain $x_{n+1}=\left(1-\alpha_{n}\right) x_{n}+\alpha_{n} T x_{n}, n \geq 0$. Since

$$
\begin{aligned}
\left\langle S x_{n}\right. & \left.-S x^{*}, j\left(x_{n}-x^{*}\right)\right\rangle-\Phi\left(\left\|x_{n}-x^{*}\right\|\right) \\
& =-\left\{\left\langle T x_{n}-x^{*}, j\left(x_{n}-x^{*}\right)\right\rangle-\left\|x_{n}-x^{*}\right\|^{2}+\Phi\left(\left\|x_{n}-x^{*}\right\|\right)\right\} .
\end{aligned}
$$

Therefore,

$$
\begin{aligned}
& \liminf _{n \rightarrow \infty} \sup _{j\left(x_{n}-x^{*}\right) \in J\left(x_{n}-x^{*}\right)}\left\{\left\langle S x_{n}-S x^{*}, j\left(x_{n}-x^{*}\right)\right\rangle-\Phi\left(\left\|x_{n}-x^{*}\right\|\right)\right\} \\
& \quad=-\limsup _{n \rightarrow \infty} \inf _{j\left(x_{n}-x^{*}\right) \in J\left(x_{n}-x^{*}\right)}\left\{\left\langle T x_{n}-x^{*}, j\left(x_{n}-x^{*}\right)\right\rangle-\left\|x_{n}-x^{*}\right\|+\Phi\left(\left\|x_{n}-x^{*}\right\|\right)\right\} .
\end{aligned}
$$

The condition (3.16) is equivalent to condition (3.2). Since $S$ is a Lipschitzian operator, $T$ is a Lipschitzian mapping. By Theorem 3.1, Theorem 3.4 holds. This completes the proof of Theorem 3.4.

\section{Acknowledgments}

This work was partially supported by the National Natural Science Foundation of China (NSFC) (Grant no. 71201093, no. 11001289, and no. 11171363), Humanities and Social Sciences Foundation of Ministry of Education of China (Grant no. 10YJCZH217), Promotive Research Fund for Excellent Young and Middle-Aged Scientists of Shandong Province (Grant no. BS2012SF012), and Independent Innovation Foundation of Shandong University, IIFSDU (Grant no. 2012TS194). 


\section{References}

[1] C. E. Chidume and C. O. Chidume, "Convergence theorems for fixed points of uniformly continuous generalized Ф-hemi-contractive mappings," Journal of Mathematical Analysis and Applications, vol. 303, no. 2, pp. 545-554, 2005.

[2] C. Moore and B. V. C. Nnoli, "Iterative solution of nonlinear equations involving set-valued uniformly accretive operators," Computers \& Mathematics with Applications, vol. 42, no. 1-2, pp. 131-140, 2001.

[3] C. E. Chidume and H. Zegeye, "Approximation methods for nonlinear operator equations," Proceedings of the American Mathematical Society, vol. 131, no. 8, pp. 2467-2478, 2003.

[4] M. O. Osilike, "Iterative solution of nonlinear equations of the $\varphi$-strongly accretive type," Journal of Mathematical Analysis and Applications, vol. 200, no. 2, pp. 259-271, 1996.

[5] M. O. Osilike, "Iterative solutions of nonlinear $\varphi$-strongly accretive operator equations in arbitrary Banach spaces," Nonlinear Analysis. Theory, Methods E Applications, vol. 36, pp. 1-9, 1999.

[6] C. H. Xiang, Z. Chen, and K. Q. Zhao, "Some convergence theorems for a class of generalized $\Phi$ hemicontractive mappings," Journal of Concrete and Applicable Mathematics, vol. 8, no. 4, pp. 638-644, 2010.

[7] K. Deimling, "Zeros of accretive operators," Manuscripta Mathematica, vol. 13, pp. 365-374, 1974.

[8] C. H. Xiang, "Fixed point theorem for generalized Ф-pseudocontractive mappings," Nonlinear Analysis. Theory, Methods \& Applications, vol. 70, no. 6, pp. 2277-2279, 2009.

[9] Y. Xu, "Ishikawa and Mann iterative processes with errors for nonlinear strongly accretive operator equations," Journal of Mathematical Analysis and Applications, vol. 224, no. 1, pp. 91-101, 1998.

[10] X. P. Ding, "Iterative process with errors to nonlinear $\varphi$-strongly accretive operator equations in arbitrary Banach spaces," Computers E Mathematics with Applications, vol. 33, no. 8, pp. 75-82, 1997.

[11] R. P. Agarwal, N. J. Huang, and Y. J. Cho, "Stability of iterative processes with errors for nonlinear equations of $\varphi$-strongly accretive type operators," Numerical Functional Analysis and Optimization, vol. 22, no. 5-6, pp. 471-485, 2001.

[12] Z. Huang, "Weak stability of Mann and Ishikawa iterations with errors for $\varphi$-hemicontractive operators," Applied Mathematics Letters, vol. 20, no. 4, pp. 470-475, 2007.

[13] S. S. Chang, K. K. Tan, H. W. J. Lee, and C. K. Chan, "On the convergence of implicit iteration process with error for a finite family of asymptotically nonexpansive mappings," Journal of Mathematical Analysis and Applications, vol. 313, no. 1, pp. 273-283, 2006.

[14] C. E. Chidume and E. U. Ofoedu, "A new iteration process for generalized Lipschitz pseudocontractive and generalized Lipschitz accretive mappings," Nonlinear Analysis. Theory, Methods $\mathcal{E}$ Applications, vol. 67, no. 1, pp. 307-315, 2007. 


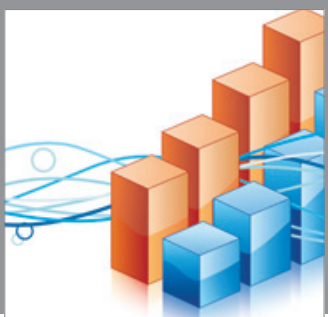

Advances in

Operations Research

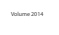

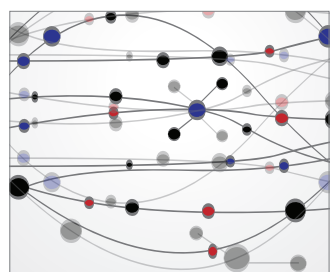

\section{The Scientific} World Journal
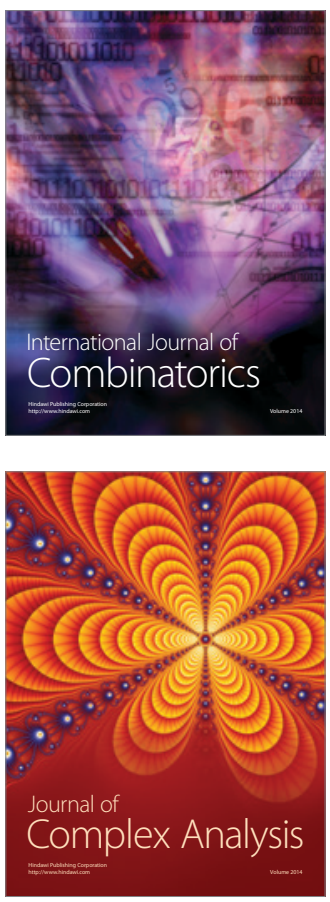

International Journal of

Mathematics and

Mathematical

Sciences
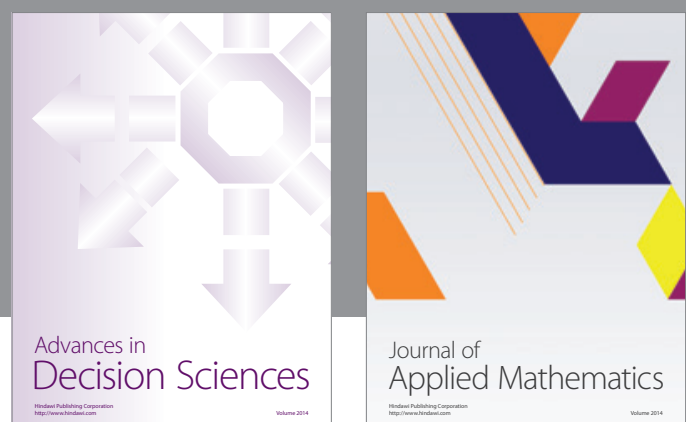

Journal of

Applied Mathematics
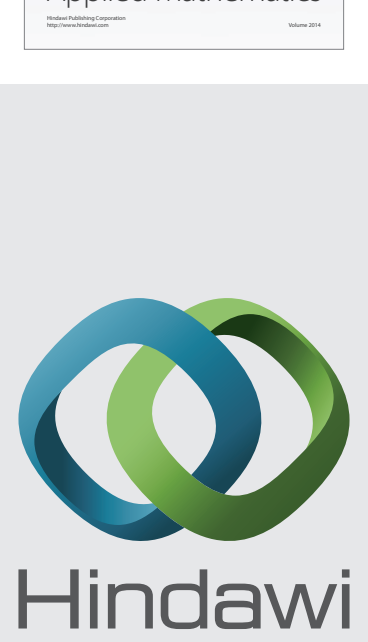

Submit your manuscripts at http://www.hindawi.com
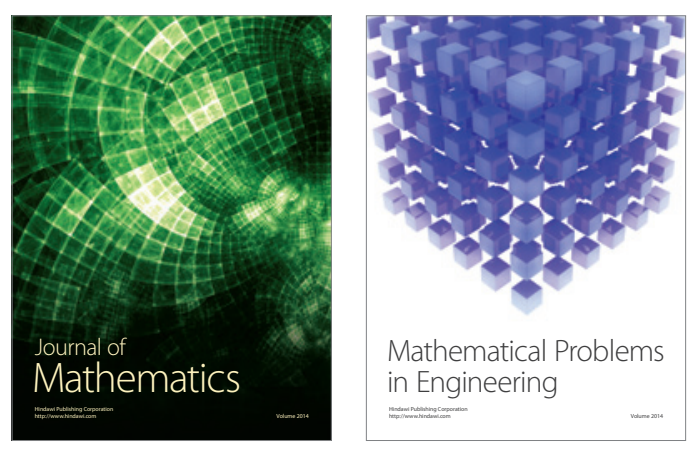

Mathematical Problems in Engineering
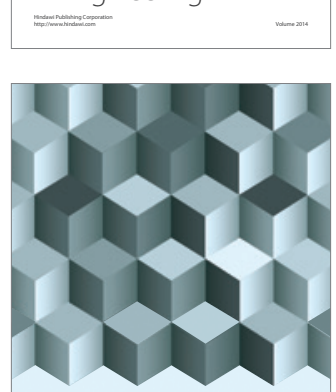

Journal of

Function Spaces
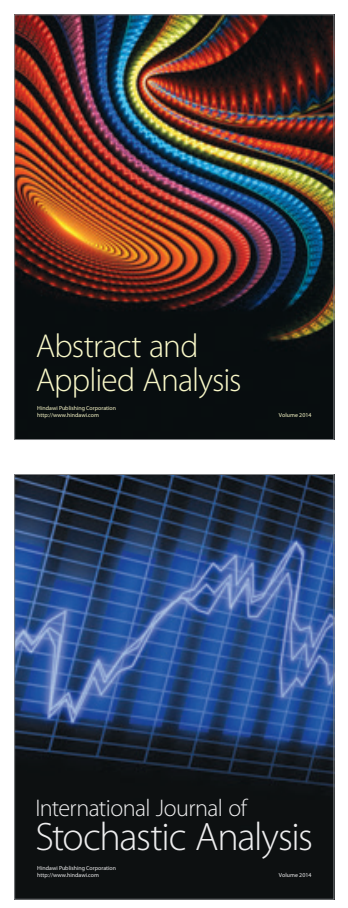

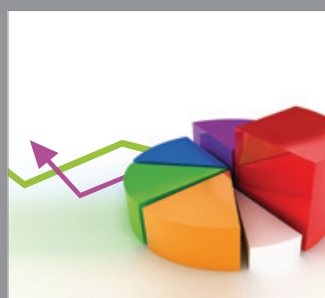

ournal of

Probability and Statistics

Promensencen
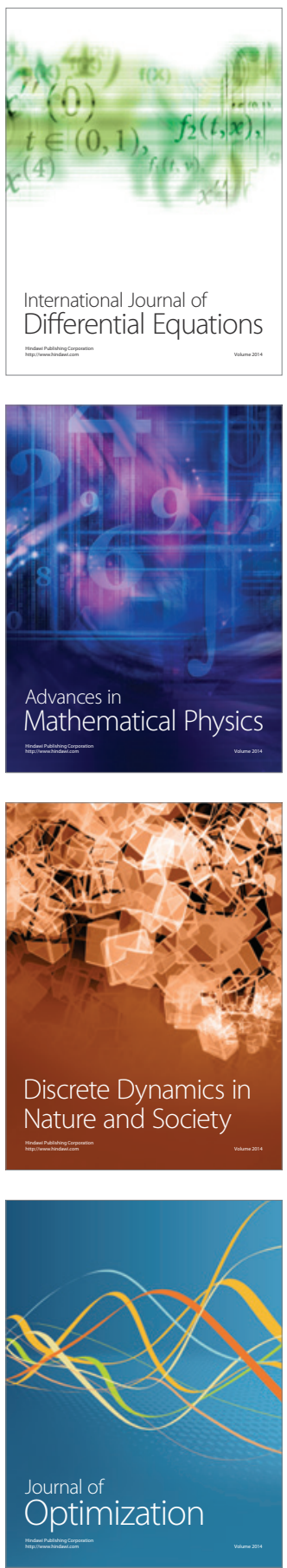